\title{
EVALUATION OF D-DIMER SERUM LEVELS AMONG PATIENTS WITH CHRONIC SPONTANEOUS URTICARIA AND ITS CORRELATION WITH DISEASE SEVERITY .
}

\author{
Dr. Aditi Jaiswal* \\ Department Of Dermatology Venereology and Leprosy. ${ }^{*}$ Corresponding \\ Author

ABSTRACT Aims: To evaluate D-Dimer serum levels in patients with chronic urticaria and its correlation with disease activity.

Settings and Design: Single centre Cross sectional prospective observational age \& sex matched case-control study at Dermatology OPD of a tertiary referral centre.

Methods and Material: This study was conducted from January 2018 to June 2019. We included 33 patients with CU and 30 controls. They were recruited from urticaria clinic. All cases were subjected to history taking, general and dermatological examination. The serum levels of D-Dimer were measured by Semiquantitative, immunofiltration kits.

Statistical analysis: Data was analysed by Statistical Package for Social Sciences (SPSS) version 21.0. Tests used were Independent $t$ test/Mann-Whitney Test, Chi-Square test/Fisher's Exact test, Spearman rank correlation coefficient, KolmogorovSmirnov test..

Results: Patients with active CU had elevated D-Dimer serum levels $(\mathrm{p}<0.0001$ ) when compared with the control group (papulosquamous disorder). Of 33 CSU patients, D-dimer level was elevated in 19 patients (57.58\%). There was statistically significant positive correlation between disease severity (UAS7) and plasma D-dimer level $(p<.0001, r=0.935$ ).

Conclusions: This study showed elevated D-dimer levels in more than half of Indian patients with CSU. There was a positive correlation between plasma D-dimer levels and the severity

of disease activity. Investigation for plasma D-dimer level may be an alternative objective way to evaluate disease severity in patients with CSU.

Limitations: Low sample size. Semi quantitative method was used instead of ELISA for D-Dimer .

\section{KEYWORDS : D-Dimer, chronic urticaria, UAS7}

\section{INTRODUCTION:}

Chronic urticaria (CU) is a widespread skin disease, characterised by the recurrence of transient wheals and itch for more than 6 week ${ }^{1}$. Chronic urticaria has wide spectrum of clinical presentations and aetiologies ${ }^{2}$ which includes mast cell activation ${ }^{3,4}$, autoimmunity ${ }^{5,6}$, auto reactivity ${ }^{7}$, basophil activation ${ }^{8}$. Besides all the above mechanisms, some part of the pathogenesis of CSU remains unclear. It was observed that the autologous plasma skin test (APST) was positive in some ASST-negative patients ${ }^{9}$ and that IgG depleted serums from CSU patients retained ability to induce a wheal-andflare reaction upon intradermal injection ${ }^{10}$. Due to these evidences it was inferred that clotting cascade may be involved in pathogenesis of urticaria. It has been observed in studies that tissue factor expressed by eosinophils can induce activation of coagulation cascade which in turn generates thrombin which can increase vascular permeability both directly by acting on endothelial cells, and indirectly by inducing degranulation of mast cells ${ }^{11}$ and also may activate protease activated receptorl (PARl) on mast cells ${ }^{12}$.In severe CSU patients, the coagulation cascade activation via extrinsic pathway is so extensive that it produces an elevation of Ddimer ${ }^{13}$. A fibrin degradation product that is D-Dimer is generated following activation of the coagulation cascade and is a sign of fibrinolysis. D-Dimer has been found to be increased during urticaria exacerbations and normalises in remission. Moreover, it has been proposed as a biomarker of severity in CSU patients ${ }^{14}$.

To date, there is no data concerning D-dimer level in Indian patients with CSU. We aim to evaluate the levels of D-Dimer level in patients with CSU and to study the correlation between D-dimer level and the activity of disease in Indian patients.

\section{SUBJECTS AND METHODS:}

This study was initiated only after obtaining approval from institutional ethics committee. It was carried out on $33 \mathrm{CSU}$ patients \& 30 controls ( patients with papulo-squamous disorder ) from Urticaria clinic at a tertiary referral centre. On the basis of the inclusion and exclusion criteria, the study population was screened and selected. Informed consent explained to the patients in their own language was obtained after which an information sheet was provided to the patients.

Inclusion criteria : All chronic spontaneous urticaria patients above 18 years, who are willing for the blood investigation with Urticaria activity score 7 (UAS7) > 12.

Exclusion criteria : Patients who had history of bleeding disorder, deep vein thrombosis, pulmonary embolism, physical urticaria, history of recent surgery, were on anticoagulants or Pregnant.

A detailed history was recorded from the patient which included onset and duration of the disease, angioedema. History of any aggravating factor such as food, drugs, exercise, comorbidities. A complete general examination, dermatological examination was performed for all patients.

Assessment of ideas activity : Urticaria Activity Score 7 (UAS 7) was calculated at the time of collection of blood. Urticaria Activity Score 7 is the daily documentation of combined score of severity of itch and number of wheals to determine disease activity. Maximum score for 7 day score is upto 42 . (Table 1$)^{15}$.

Table 1 : Urticaria activity score 7

\begin{tabular}{|c|c|c|}
\hline Score & Wheals & Pruritus \\
\hline 0 & None & None \\
\hline 1 & $\begin{array}{c}\text { Mild } \\
\text { (<20 wheals/24 hour })\end{array}$ & $\begin{array}{c}\text { Mild } \\
\text { ( present but not } \\
\text { troublesome / or only at } \\
\text { rest) }\end{array}$ \\
\hline 2 & $\begin{array}{c}\text { Moderate } \\
\text { wheals / } 24 \text { hours })\end{array}$ & $\begin{array}{c}\text { Moderate } \\
\text { (troublesome but does } \\
\text { not interfere with sleep })\end{array}$ \\
\hline 3 & $\begin{array}{c}\text { Intense ( }>50 \text { wheals/ } 24 \\
\text { hour) }\end{array}$ & $\begin{array}{c}\text { Intense } \\
\text { (severe pruritus which } \\
\text { interferes with sleep ) }\end{array}$ \\
\hline
\end{tabular}


D-Dimer evaluation:

$2 \mathrm{ml}$ of venous blood was collected under aseptic precaution in sodium citrate bulb during the period of disease activity for estimation.The sample was transported to the lab within 3 hours. The serum was centrifuged at $1500 \mathrm{G}$ for 15 minutes. Then the platelet poor plasma was separated in another tube which underwent double spin. This sample was used for testing. D-dimer plasma level was measured by Semiquantitative, immunofiltration kits. The cut-off level is 500 $\mathrm{ng} / \mathrm{mL}$.

\section{Statistical Analysis:}

Categorical variables were presented in number and percentage (\%) and continuous variables were presented as mean $\pm \mathrm{SD}$ and median. Normality of data was tested by Kolmogorov-Smirnov test. Statistical tests were applied as follows-

1. Quantitative variables were compared using Independent $t$ test/Mann-Whitney Test (when the data sets were not normally distributed) between the two groups.

2. Qualitative variables were correlated using Chi-Square test/Fisher's Exact test.

3. Spearman rank correlation coefficient was used to assess the association of various parameters with $\mathrm{D}$-dimer and UAS 7.

p value of $<0.05$ was considered statistically significant.

The data was entered in MS EXCEL spreadsheet and analysis was done using Statistical Package for Social Sciences (SPSS) version 21.0

Results:

The study included 22 (66.67\%) females and 11 (33.33\%) males their age ranging between 18 to 65 years with mean \pm SD of 31.97 years \pm 9.83 amongst CSU group. And control group had 17 (56.67\%) female and 13 (43.33\%) Males with mean \pm SD of $36.3 \pm 12.05$.

The disease duration ranged between 2 - 36 months with mean \pm SD $9.27 \pm 7.8$ (Table 2)

Table 2: demographic data of subjects $(n=63)$

\begin{tabular}{|c|c|c|c|c|}
\hline & \multicolumn{2}{|c|}{ Case } & \multicolumn{2}{c|}{ Control } \\
\hline & Number & $\%$ & Number & $\%$ \\
\hline Gender & & & & \\
\hline male & 11 & 33.33 & 13 & 43.33 \\
\hline female & 22 & 66.67 & 17 & 56.67 \\
\hline Age & & & & \\
\hline Min-max & \multicolumn{2}{|c|}{$18-65$} & \multicolumn{2}{c|}{$18-65$} \\
\hline $\begin{array}{c}\text { mean } \pm \\
\text { SD }\end{array}$ & $31.97 \pm 9.83$ & \multicolumn{2}{c|}{$36.3 \pm 12.05$} \\
\hline median & \multicolumn{2}{|c|}{30} & \multicolumn{2}{c|}{36.5} \\
\hline
\end{tabular}

Out of the 63 patients tested for D-Dimer, in patients with severe CSU, mean value of D-Dimer ( $697.12 \mathrm{ng} / \mathrm{ml}$ ) largely exceeded from those found in control ( 129.87) giving significant p-value (0.0001) [ Figure 1].

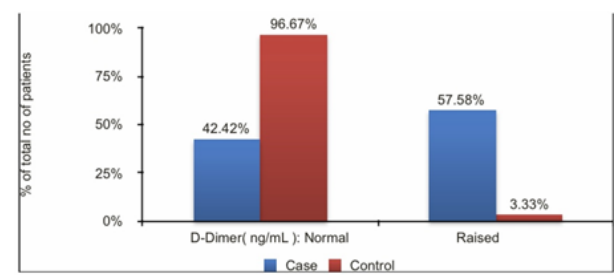

Figure 1: Distribution of cases \& controls according to DDimer

Amongst the enrolled CSU cases, normal plasma D-dimer level was observed in (42.42\%) and elevated plasma D-dimer level was in (57.58\%). We observed a statistically significant positive correlation between UAS7 \& D-dimer $(\mathrm{p}<.0001, \mathrm{r}$ $=0.935$ ) [ Figure 2].

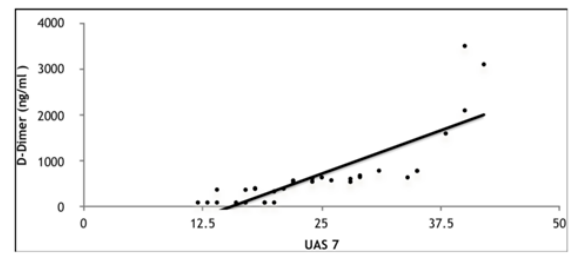

Figure 2: Correlation between UAS 7 \& D-Dimer (ng/ml)

It was observed that the higher UAS7 i.e. $32-42$ showed elevated D-Dimer in $99 \%$ patients. Whereas moderate severity urticaria (UAS7 12-30) showed 56\% with normal Dimer and $44 \%$ with elevated D-Dimer. [Figure 3]

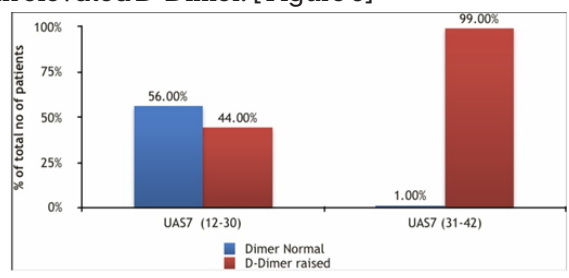

Figure 3:Distribution of cases depending on severity and DDimer

The mean age of elevated D-Dimer levels in patients of CSU is 32 years i.e common in 3rd decade with a female predominance. The average duration of disease in D-Dimer positive patients is 8 months. We also observed that as the duration increased D-Dimer levels reduced [ Figure 4 ].

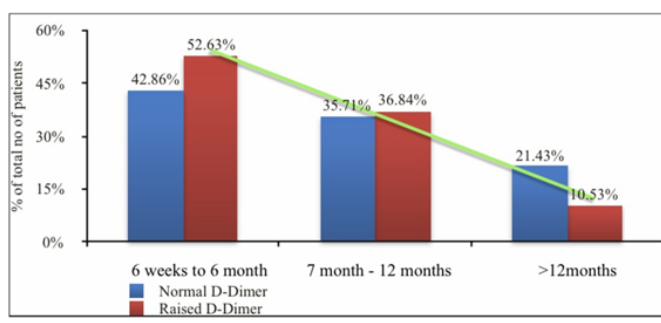

Figure 4: Correlation between Duration of the disease \& DDimer levels ( $\mathrm{ng} / \mathrm{ml}$ )

Out of 33 patients in our study, 14 patients had either history of angio-oedema. Out of these 14 patients, 9 ( $64.28 \%$ ) showed raised D-Dimer and 5 ( $35.71 \%)$ showed normal D-Dimer levels (Table 3). 2 patients of CSU had hypothyroidism and we observed that they had elevated D-Dimer levels. But no statistically significant correlation could be found between the two parameter.

Table 3 : Comparison between and angioedema and DDimer

\begin{tabular}{|l|c|c|c|}
\hline & $\begin{array}{c}\text { Angioedema } \\
\text { present }\end{array}$ & $\begin{array}{c}\text { Angiodema } \\
\text { absent }\end{array}$ & P-value \\
\cline { 1 - 3 } D-Dimer Raised & 9 & 10 & $0.503(\mathrm{NS})$ \\
\cline { 1 - 3 } D-Dimer Normal & 5 & 9 & \\
\cline { 1 - 3 } & & \multicolumn{2}{|c}{}
\end{tabular}

\section{DISCUSSION:}

Urticaria is a common disease which has a negative impact on quality of life of the patients. The disease carries a significant emotional and economic burden on the patient ${ }^{16}$. In order to provide adequate treatment to the patients, the evaluation of disease severity and activity is essential. But there is no reliable biomarker for such evaluations and it solely depends on subjective description. The involvement of coagulation cascade in pathophysiology of urticaria was proposed in a few studies ${ }^{13,17}$. The markers of thrombin generation and fibrinolysis was elevated in urticaria was noticed ${ }^{18,19}$. 
Epidemiologically, among the group with elevated D-Dimer, female outnumbered male which was similar to what is known ${ }_{14,20}$ with mean age being 32 years i.e common in 3rd decade. Out of 33 patients in our study, 14 patients had either history of angio-oedema or presented with it. Out of these 14 patients, 9 ( $64.28 \%$ ) showed raised D-Dimer levels. In the study by Alwafa et $\mathrm{al}^{21} 32.5 \%$ and by of Sabroe et $a l^{[22]} 85 \%$ patients had $\alpha$ history of positive angioedema. 2 patients of CSU had hypothyroidism and we observed that they had elevated DDimer levels. But no statistically significant correlation could be found between the two parameters.

In this study we found normal plasma D-dimer level in $(42.42 \%)$ of enrolled CSU patients and elevated plasma Ddimer level in $(57.58 \%)$ of them. Previous studies showed increased D-Dimer level in $54.5 \%$ by Criado et $\alpha^{14}, 37.5 \%$ by Alwafa et $\mathrm{al}^{21}$, Triwongwaranat et $\mathrm{al}^{23}$ found elevated D-dimer levels in $48.3 \%$, in $35 \%$ by Takahagi $\mathrm{S}^{18}$. Similar findings were also observed by Asero et $\mathrm{al}^{24}$. The difference in observations may be due to difference in severity of patient selected.

Our study also showed the positive correlation between plasma D-dimer level and disease severity $(p<.0001$, $r$ $=0.935$ ). Similar correlation was also observed in few other studies ${ }^{23,24,25}$. We observed that the patients with severe urticaria had mean level of D-Dimer ( $1047.1 \mathrm{ng} / \mathrm{ml} \pm 889.68$ ) which largely exceeded those found in moderate urticaria ( $222.14 \mathrm{ng} / \mathrm{ml} \pm 147.17)$. Asero et al ${ }^{24}$ also observed that median level in chronic urticaria exceeded from that in moderate urticaria and in controls. The coagulation cascade activation and fibrinolysis that is exaggerated in exacerbation decreases till it complete normalises during remission of $\mathrm{CSU}^{24}$.

\section{CONCLUSION :}

This study showed elevated plasma D-dimer levels in more than half of Indian patients with CSU and there was a positive correlation between plasma D-dimer levels and the severity of disease activity. We would like to conclude by saying that plasma D-dimer levels may be an alternative objective way to evaluate disease severity in patients with CSU.

\section{LIMITATIONS:}

- Low sample size.

- Semi quantitative method was used instead of ELISA for D-Dimer .

\section{REFERENCES:}

1. Tedeschi A, Kolkhir P, Asero R, Pogorelov D, Olisova O, Kochergin N et al. Chronic urti-caria and coagulation: pathophysiological and clinical aspects. Allergy Eur J Allergy Clin Immunol 2014;69:683-91. doi:10.1111/all.12389

2. Godse KV. Chronic urticaria and treatment options. Indian J Dermatol 2009;54:310-2.

3. Bressler RB. Pathophysiology of urticaria. Immunol Allergy Clin N Am 1995; 15:659-77.

4. Greaves MW. Chronic Urticaria. N Engl J Med. 1995;332:1767-72. doi:10.1056/NEJM199506293322608

5. Konstantinou GN, Asero R, Maurer M, Sabroe RA, Schmid Grendelmeier P, Grattan CEH. EAACI/GA2LEN task force consensus report: the autologous serum skin test in urticar-ia. Allergy Eur J Allergy Clin Immunol. 2009;64:125668. doi:10.1111/j.1398-9995.2009.02132.x.

6. Nimii N, Francis DM, Kermani F, et al. Dermal mast cell activation by autoantibodies against the high affinity IgE receptor in chronic urticaria. J Invest Dermatol 1996;106: 1001-10.

7. Chang TW, Chen C, Lin CJ, Metz M, Church MK, Maurer M. The potential pharmacologic mechanisms of omalizumab in patients with chronic spontaneous urticaria. J Allergy Clin Immunol. 2015;135:337-42.

8. Grattan CEH, Walpole D, Francis DM, et al. Flow cytometric analysis of basophil numbers in chronic urticaria: basopenia is related to serum histamine releasing activity. Clin Exp Allergy 1997;27:1417-24.

9. Asero R, Tedeschi A, Riboldi P, Cugno M. Plasma of patients with chronic urticaria shows signs of thrombin generation, and its intradermal injection causes wheal-and-flare reac-tions much more frequently than autologous serum. J Allergy Clin Immunol. 2006; 117:1113-7.

10. Fagiolo U, Kricek F, Ruf C, Peserico A, Amadori A, Cancian M. Effects of comple-ment inactivation and IgG depletion on skin reactivity to autologous serum in chronic idiopathic urticaria. J Allergy Clin Immunol 2000;106:567-72.

11. Ver Elst K.et al Plasma D-Dimer concentrations in different clinical conditions. Acta Clin Belg 2002;57:325-30.

12. Vliagoftis $\mathrm{H}$. Thrombin induces mast cell adhesion to fibronectin: evidence for in-volvement of protease-activated receptor-1. J Immunol 2002; 169:4551-8.

13. Cugno M, Marzano V, Asero R, Tedeschi A. Activation of blood coagulation in chronic urticaria: pathophysiology and clinical implications. Intern Emerg Med 2010;5:97-101.

14. Criado PR, Antinori LC, Maruta CW, Reis VM. Evaluation of D-dimer serum levels among patients with chronic urticaria, psoriasis and urticarial vasculitis. An Bras Derma-tol. 2013;88:355-60. doi:10.1590

15. Zuberbier T, Aberer W, Asero R, Bindslev-Jensen C, Brzoza Z, Canonica GW, et al. The EAACI/GA(2) LEN/EDF/WAO Guideline for the definition, classification, diag-nosis, and management of urticaria: the 2013 revision and update. Allergy. 2014;69:868-887. doi: 10.1111/all.12313.

16. Dias G.A.C, Pires G.V, do Valle S.O.R, Dortas S.D, Levy S, França A.T, et al Impact of chronic urticaria on the quality of life of patients followed up at a university hospital. An. Bras. Dermatol. 2016;91:754-59.

17. Asero R, Riboldi P, Tedeschi A, Cugno M, Meroni P. Chronic urticaria: $a$ disease at a crossroad between autoimmunity and coagulation. Autoimmun Rev 2007;7:71-6.

18. Takahagi S, Mihara S, Iwamoto K, Morioke S, Okabe T, Kameyoshi Y et al. Coagula-tion/ fibrinolysis and inflammation markers are associated with disease activity in pa-tients with chronic urticaria. Allergy. 2010;65:649 56.

19. Wang F, Tang H, Xu J, Kang K. Activation of the blood coagulation cascade is in-volved in patients with chronic urticaria. J Allergy Clin Immunol 2009;123:972-3.

20. Kanani $\mathrm{A}$, Betschel SD, Warrington R. Urticaria and angioedema. Allergy Asthma Clin Immunol. 2018;14:59. doi: 10.1186/s13223-018-0288-z

21. Alwafa HOA, Mohammed MF, Mohammed YR. Evaluation of plasma d-dimer level in patients with chronic urticaria. J Dermat Cosmetol. 2019;3:7 11.

22. Sabroe RA, Fiebiger E, Francis DM, et al. Classification of anti-Fc epsilonRI and anti-IgE autoantibodies in chronic idiopathic urticaria and correlation with disease severity. J Allergy Clin Immunol. 2002;1 10:492 99.

23. Triwongwaranat D, Kulthanan K, Chularojanamontri L, Pinkaew S Correlation be-tween plasma D-dimer levels and the severity of patients with chronic urticaria. Asia Pac Allergy 2013;3:100-5.

24. Asero R, Tedeschi A, Riboldi P, Griffini S, Bonani E, Cugno M. Severe chronic urticar-ia is associated with elevated plasma level of D-dimer. Allergy 2008;63:176-80.

25. Park BW, Jang YJ, Cho EB, Park EJ, Kim KH, Kim KJ. The role and relationship of serum D-Dimer level and autologous serum skin test response In chronic spontaneous urticaria. Dermatol Sin 2019;37:67-71. 